\title{
The Biological Behaviors of Rat Dermal Fibroblasts Can Be Inhibited by High Levels of MMP9
}

\author{
Sheng-Neng Xue, ${ }^{1}$ Juan Lei, ${ }^{2}$ Chuan Yang, ${ }^{1}$ Diao-Zhu Lin, ${ }^{1}$ and Li Yan' \\ ${ }^{1}$ Department of Endocrinology, Sun Yat-Sen Memorial Hospital, Sun Yat-Sen University, 107 Yan Jiang West Road, \\ Guangzhou 510120, China \\ ${ }^{2}$ Department of Cardiology, Sun Yat-Sen Memorial Hospital, Sun Yat-Sen University, 107 Yan Jiang West Road, \\ Guangzhou 510120, China \\ Correspondence should be addressed to Li Yan, hfxyl@163.net
}

Received 27 October 2011; Revised 22 February 2012; Accepted 27 February 2012

Academic Editor: Maria Irigoyen

Copyright () 2012 Sheng-Neng Xue et al. This is an open access article distributed under the Creative Commons Attribution License, which permits unrestricted use, distribution, and reproduction in any medium, provided the original work is properly cited.

\begin{abstract}
Aims. To explore the effects of the high expression of MMP9 on biological behaviors of fibroblasts. Methods. High glucose and hyperhomocysteine were used to induce MMP9 expression in skin fibroblasts. Cell proliferation was detected by flow cytometry and cell viability by CCK-8. ELISA assay was used to detect collagen (hydroxyproline) secretion. Scratch test was employed to evaluate horizontal migration of cells and transwell method to evaluate vertical migration of cells. Results. The mRNA and protein expressions of MMP9 and its protease activity were significantly higher in cells treated with high glucose and hyperhomocysteine than those in control group. At the same time, the S-phase cell ratio, proliferation index, cell viability, collagen (hydroxyproline) secretion, horizontal migration rate, and the number of vertical migration cells decreased in high-glucose and hyperhomocysteinetreated group. Tissue inhibitor of metalloproteinase 1 (TIMP1), which inhibits the activity of MMP9, recovered the above biological behaviors. Conclusions. High expression of MMP9 in skin fibroblasts could be induced by cultureing in high glucose and hyperhomocysteine medium, which inhibited cell biological behaviors. Inhibitions could be reversed by TIMP1. The findings suggested that MMP9 deters the healing of diabetic foot ulcers by inhibiting the biological behaviors of fibroblasts.
\end{abstract}

\section{Introduction}

It is well known that ulcers of diabetic foot are refractory and can cause considerable morbidity and mortality [1]. In recent years, domestic and international studies have found that increased matrix metalloproteinases (MMPs) expression would contribute to the vulnerability of diabetic skin and the refractory nature of diabetic foot ulcers, especially MMP9 $[2,3]$. MMPs are proteinases that participate in extracellular matrix macromolecule degradation. MMP9 is one of this growing family. An important mechanism for the regulation of the activity of MMPs is via binding to members of the family of proteins referred to as tissue inhibitor of metalloproteinases (TIMPs). Our previous studies have shown that local abnormal expression of MMP9 in the skin was correlated with skin damage. As compared with nondiabetic rats, the process of wound healing in the skin slowed down in diabetic rat and, at the same time, levels of MMP9 increased significantly, while TIMP1, the tissue-specific inhibitor of MMP9, decreased in the diabetic group [4-6].

It is widely recognized that high levels of MMP9 slow down the healing of diabetic foot ulcers by excessive degradation of extracellular matrix, growth factors, growth factor receptors, integrins, and their receptors, as well as increasing the local inflammatory response in the wound [7-9]. It is still unknown whether MMP9 can influence the biological behaviors of skin fibroblasts and affect wound healing. Skin fibroblasts play important roles in wound repairing. Anything that can affect their biological properties will ultimately affect wound healing. To investigate the mechanisms of MMP9 in diabetic foot wound healing, rat skin fibroblasts were cultured in high glucose and hyperhomocysteine medium [10-12]. Changes of biological behaviors of skin fibroblasts were observed before and after using the exogenous TIMP1. 


\section{Methods}

2.1. Cell Culture and Grouping. Fibroblasts (CRL-1213, ATCC, USA) were cultured in DMEM (Gibco, USA) containing $10 \%$ fetal bovine serum (FBS, Hyclone, USA) in a $\mathrm{CO}_{2}$ incubator $\left(37^{\circ} \mathrm{C}, 5 \% \mathrm{CO}_{2}\right)$. After 24 -hour serum deprivation $(0.5 \%$ FBS $)$, fibroblasts were cultured in DMEM containing $10 \% \mathrm{FBS}$ at three different conditions (according to the grouping) for 6 hours in a $\mathrm{CO}_{2}$ incubator $\left(37^{\circ} \mathrm{C}, 5 \% \mathrm{CO}_{2}\right)$.

Grouping: (1) Control group was cultured in DMEM containing normal glucose $(5.5 \mathrm{mmol} / \mathrm{L})$. (2) Model group was cultured in DMEM containing glucose $(22.0 \mathrm{mmol} / \mathrm{L})$ and homocysteine $(100 \mu \mathrm{mol} / \mathrm{L})$ [10-12]. (3) TIMP1 group was cultured in DMEM containing glucose $(22.0 \mathrm{mmol} / \mathrm{L})$, homocysteine $(100 \mu \mathrm{mol} / \mathrm{L})$, and TIMP1 $(100 \mu \mathrm{g} / \mathrm{L}, \mathrm{R}$ and D Systems, Minneapolis, USA).

2.2. Determination of MMP9 Levels. MMP9 mRNA expression was determined by real-time polymerase chain reaction (real-time-PCR) [13]. Total RNA was extracted by Trizol (Invitrogen, Carlsbad, CA, USA) from cells. To quantify MMP9 mRNA levels by real-time-PCR, GAPDH was used as the internal control. Primers were designed by Invitrogen Corporation (Carlsbad, CA, USA) according to the sequences of rat MMP9 and GAPDH in GeneBank. Rat MMP9 primers were sense, $5^{\prime}$ - TCCAGTAGACAATCCTTGCAATGTG-3' ; anti-sense, 5' -CTCCGTGATTCGAGAACTTCCAATA-3' ${ }^{\prime}$. Rat GAPDH primers were sense, $5^{\prime}$-GGCACAGTCAAGGCTGAGAATG-3' ; anti-sense, 5' -ATGGTGGTGAAGACGCCAGTA-3'. Amplification was performed according to the instructions of the SYBR PrimeScript PCR Kit (Takara, Kyoto, Japan). Briefly, SYBR Premix Ex TaqTM $(2 \times) 10 \mu \mathrm{L}$, PCR Forward Primer $(10 \mu \mathrm{M}) 0.4 \mu \mathrm{L}$, PCR Reverse Primer $(10 \mu \mathrm{M}) 0.4 \mu \mathrm{L}$, ROX Reference Dye $(50 \times) 0.4 \mu \mathrm{L}$, and cDNA template $2.0 \mu \mathrm{L}$ were added into a microfuge tube along with distilled water to make a total volume of $20.0 \mu \mathrm{L}$. The PCR reactions were performed in a LightCycler 480 real-time-PCR system (Roche, Basel, Switzerland), with denaturation at $95^{\circ} \mathrm{C}$ for $30 \mathrm{sec}$, then 40 cycles of $95^{\circ} \mathrm{C}$ for $5 \mathrm{sec}$ followed by elongation at $60^{\circ} \mathrm{C}$ for $20 \mathrm{sec}$. In order to ensure equal sample sizes, the real-timePCR for GADPH was performed at the same time. Melting curve analysis was conducted to ensure the specificity of amplification, the products were quantitated by the $2^{-\Delta \Delta C T}$ method, and the difference between the Ct values of MMP9 and the corresponding value of GADPH in each sample was used as the relative MMP9 Ct value.

MMP9 protein was measured by ELISA assay. At the end of cells culture, supernatants were collected. Doubleantibody sandwich ABC-ELISA was used to detect protein expression of MMP9. Operation was performed according to the instructions of the rat MMP9 ELISA kit (Uscn Life Science Inc., Wuhan, China).

MMP9 protease activity in cell culture supernatants were assessed by gelatin zymography [14]. Equal aliquots of conditioned culture media from an equal number of cells were fractionated using precast zymogram gels containing gelatin, according to the manufacturer protocol (GuangDong Chemicalreagent Inc., Guangzhou, China). After electrophoresis, gels were incubated in renaturing buffer $(50 \mathrm{mmol} / \mathrm{L}$ Tris$\mathrm{HCl}$ (pH 7.4), 2\% (vol/vol) Triton X-100) for $30 \mathrm{~min}$ at room temperature and then incubated in developing buffer (50 mmol/L Tris- $\mathrm{HCl}$ (pH 8.0), $2.5 \mathrm{mmol} / \mathrm{L} \mathrm{CaCl}, 0.02 \%$ (wt/vol) Brij-35) for $72 \mathrm{~h}$ at $37^{\circ} \mathrm{C}$. Lytic bands corresponding to the latent form of MMP9 $(92 \mathrm{kDa})$ were analyzed as total activity and visualized by staining with $0.5 \%$ (wt/vol) Coomassie Brilliant Blue solution. The gels were photographed, followed by analysis using Image Quant 5.2 software.

2.3. Proliferation of Cells. Proliferation of cells was assessed by flow cytometry [15]. Cells were collected into the dedicated tube for flow cytometry and centrifuged for $6 \mathrm{~min}$ $(2500 \mathrm{r} / \mathrm{min})$, and supernatant was discarded. Cells were resuspended with $1 \mathrm{~mL}$ PBS. Then $300 \mu \mathrm{L}$ of cell suspension was added into $700 \mu \mathrm{L}$ ice-cold ethanol drop by drop, fixed overnight at $4^{\circ} \mathrm{C}$ in the dark. On the next day, suspension was centrifuged for $10 \mathrm{~min}(2500 \mathrm{r} / \mathrm{min})$ and supernatant was discarded. Cells were resuspended again with $500 \mu \mathrm{L}$ PBS containing RNase A $(100 \mathrm{U} / \mathrm{mL})$, incubated for $30 \mathrm{~min}$ at $37^{\circ} \mathrm{C}$. Then ethidium bromide $(2 \mathrm{mg} / \mathrm{mL})$ was added to a final concentration of $50 \mu \mathrm{g} / \mathrm{mL}$ and incubated for $30 \mathrm{~min}$ in the dark. Cells cycle was detected by standard procedures of flow cytometry, and the S-phase cell ratio and proliferation index were calculated at the same time. S-phase cell ratio is $\mathrm{S} /(\mathrm{G} 0 / \mathrm{G} 1+\mathrm{S}+\mathrm{G} 2 / \mathrm{M})$; proliferation index is $(\mathrm{S}+\mathrm{G} 2 / \mathrm{M}) /$ $(\mathrm{G} 0 / \mathrm{G} 1+\mathrm{S}+\mathrm{G} 2 / \mathrm{M})$.

2.4. Viability of Cells. Viability of cells was assessed by CCK8 (Dojindo Laboratories, Kumamoto, Japan) [16]. Cells were inoculated to 96-well plates according to the density of 2.0$3.0 \times 10^{3}$ cells for each well. Premixed CCK- 8 and medium $(10 \mu \mathrm{L}: 100 \mu \mathrm{L})$ were added into 96 -well plates, and cells were then incubated for $0.5-1 \mathrm{~h}$ at $37^{\circ} \mathrm{C}$. The values of $\mathrm{A} 450$ were obtained with the 3,550 automatic detector from Beckman (Brea, CA).

2.5. Collagen (Hydroxyproline) Secretion. Collagen (hydroxyproline) secretion was detected by ELISA. Hydroxyproline was measured according to the instructions of the rat hydroxyproline ELISA kit (Xinqidi Biological Technology Co., Wuhan, China). The concentration of hydroxyproline was calculated according to the A450 value obtained with the 3,550 automatic detector from Beckman (Brea, CA).

2.6. Horizontal Migration of Cells. Horizontal migration was assessed by scratch test [17]. Cells cultured in 6-well plates were scratched with a small tip along the ruler. Washing the scratch area was repeated with PBS until the cells in this area were removed thoroughly. Adding the purpose medium and culturing $6 \mathrm{~h}$, we chose five different horizons under the inverted microscope and measured the distance between cells at $0 \mathrm{~h}$ and $6 \mathrm{~h}$ after scratching, taking the average for horizontal migration rate. Horizontal migration rate is (width at $0 \mathrm{~h}-$ width at $6 \mathrm{~h}$ )/width at $0 \mathrm{~h} \times 100 \%$.

2.7. Vertical Migration of Cells. Transwell was used to evaluate the vertical migration of cells [18]. Cells in the 


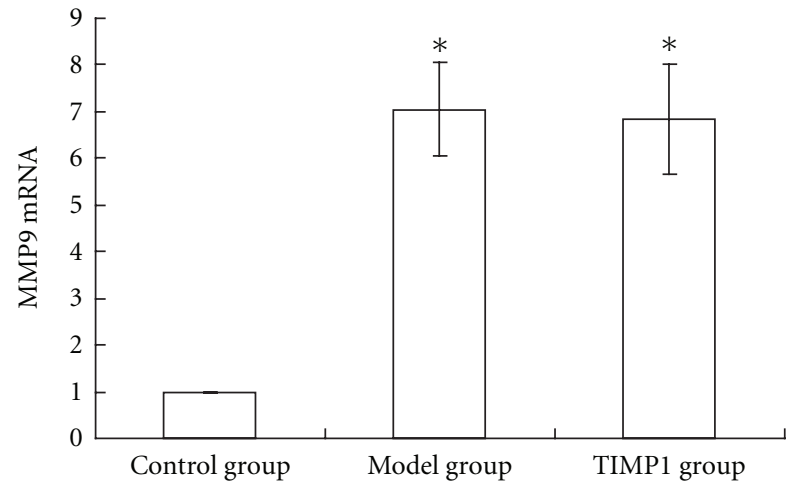

(a)

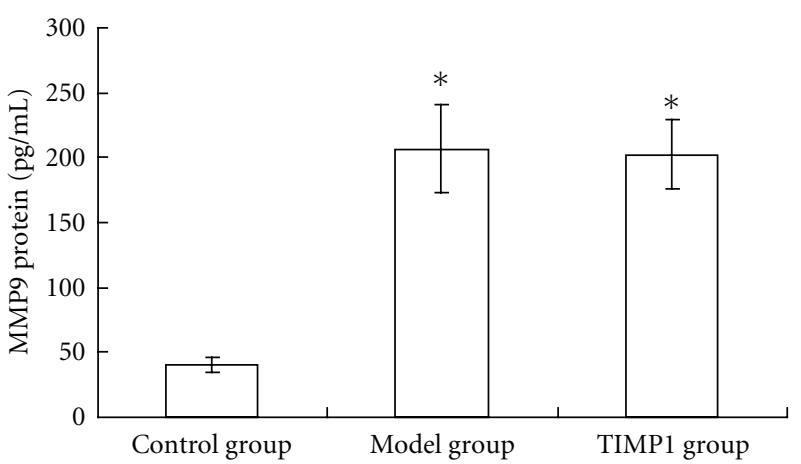

(b)

FIGURE 1: Establishment of the fibroblasts cell model of high matrix metalloproteinase 9 (MMP9) expression. The expressions of MMP9 mRNA, protein levels, and protease activity in model group were 6.05-, 4.12-, and 1.62-fold, respectively, greater than those in control group, which suggested that high expression of MMP9 was induced. When the cells were treated with tissue inhibitor of metalloproteinase 1 (TIMP1), the expression of MMP9 mRNA and protein had no statistical differences compared with model group. ${ }^{*} P<0.01$ versus control group. Data are mean $\pm \operatorname{SEM}, n=5$.

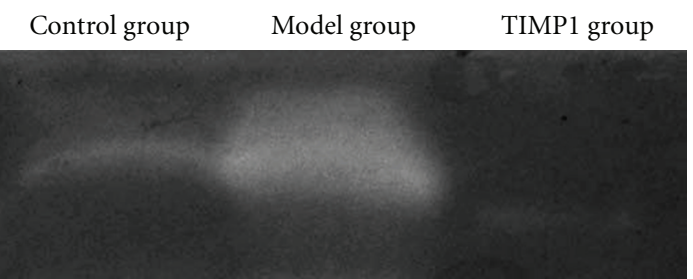

(a)

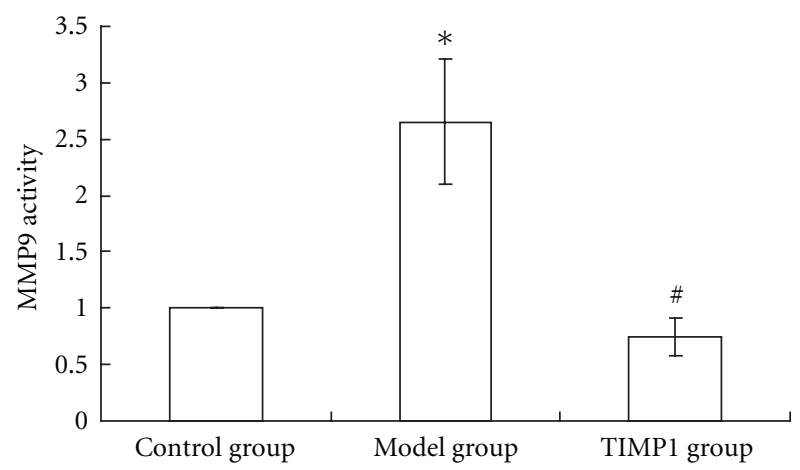

(b)

Figure 2: Matrix metalloproteinase 9 (MMP9) activity detected by Gelatin zymography. The activity of MMP9 in model group was 1.62 -fold greater than that in control group. When the cells were treated with tissue inhibitor of metalloproteinase 1 (TIMP1), the activity of MMP9 decreased by $70.7 \%$ compared with model group. ${ }^{*} P<0.01$ versus control group; ${ }^{\#} P<0.01$ versus model group. Data are mean \pm SEM, $n=5$.

logarithmic growth phase were suspended by purpose medium containing $0.5 \%$ FBS after conventional digestion. $100 \mu \mathrm{L}$ cell suspensions $\left(1.0 \times 10^{5} / \mathrm{mL}\right)$ were added into the upper chamber, and $500 \mu \mathrm{L}$ purpose medium (according to the grouping) containing 10\% FBS was added into the lower chamber. After $16 \mathrm{~h}$ of culture, the upper chamber was removed, fixed for 30 min with $4 \%$ paraformaldehyde, and stained for $15 \mathrm{~min}$ with crystalline violet. We selected four visions randomly to count the number of cells moved to the lower of the membrane under inverted microscope, taking the average for the number of vertical migration cells.

2.8. Statistical Analysis. Data are presented as mean \pm SEM. Comparisons were made by one-way ANOVA followed by Student-Newman-Keuls post hoc analysis. Data were analyzed with Microsoft Excel 2003 (Microsoft Inc., Seattle, WA, USA) and SPSS 12.0 for Windows (SPSS Inc., Chicago, IL, USA). Statistical analyses were performed using the average results of three repeated experiments under identical conditions. A $P$ value $<0.05$ was considered statistically significant. Differences were considered significant if $P<0.05$.

\section{Results}

3.1. Establishment of the Fibroblast Cell Model of High MMP9 Expression. High glucose and high homocysteine induced MMP9 expression obviously. mRNA and protein expression and protease activity of MMP9 in model group were 6.05-, $4.12-$, and 1.62-fold, respectively, higher than those in control group $(P<0.01)$. This suggested that the fibroblasts cell model of high MMP9 expression was created successfully. When the cells were treated with TIMP1 $(100 \mu \mathrm{g} / \mathrm{L})$, MMP9 protease activity decreased by $70.7 \%$ significantly $(P<$ 0.01), while MMP9 mRNA and protein expression had no statistical differences compared with those in model group $(P>0.05)$ (Figures 1 and 2).

3.2. Inhibition of Fibroblasts Proliferation, Viability, and Collagen Secretion by High MMP9 Expression. Compared with those in control group, fibroblasts proliferation, viability, and collagen secretion in model group were inhibited with $29.8 \%$ of S-phase cell ratio, $18.1 \%$ of proliferation index, $23.3 \%$ of cell viability, and $68.7 \%$ of collagen secretion $(P<0.01$, 
TABle 1: Proliferation, viability, and collagen secretion of fibroblasts.

\begin{tabular}{lcccc}
\hline Group & S-phase cell ratio $(\%)$ & Proliferation index $(\%)$ & CCK-8 OD value & Hydroxyproline $(\mathrm{pg} / \mathrm{mL})$ \\
\hline Control group & $9.31 \pm 0.24$ & $13.8 \pm 0.5$ & $1.76 \pm 0.13$ & $1126.4 \pm 62.7$ \\
Model group & $6.54 \pm 0.29^{*}$ & $11.3 \pm 0.6^{*}$ & $1.35 \pm 0.12^{*}$ & $352.8 \pm 60.6^{*}$ \\
TIMP1 group & $7.75 \pm 0.27^{* \#}$ & $12.5 \pm 0.5^{* \S}$ & $1.64 \pm 0.14^{\#}$ & $828.6 \pm 58.9^{* \#}$ \\
\hline
\end{tabular}

TIMP1: tissue inhibitor of metalloproteinase $1 ;{ }^{*} P<0.01$ versus control group; ${ }^{\S} P<0.05 ;{ }^{\#} P<0.01$ versus model group. Data are mean \pm SEM, $n=5$.

resp.). After treatment with TIMP1, the inhibition reduced compared with those in model group $(P<0.05)$ (Table 1$)$.

\subsection{Inhibition of Fibroblasts Horizontal Migration by High MMP9 Expression. The horizontal migration rate of fibrob- lasts in model group $(21.3 \pm 2.1) \%$ was lower than that in control group $(38.7 \pm 2.6) \%$ with the inhibition rate being 45.0\% $(P<0.01)$. After treatment with TIMP1, the horizon- tal migration rate $(31.5 \pm 2.7) \%$ increased compared with that in model group but failed to recover to the level of control group $(P<0.01$, resp.) (Figure 3$)$.}

3.4. Inhibition of Fibroblasts Vertical Migration by High MMP9 Expression. Compared with control group (90.6 \pm $3.8)$, the vertical migration of cells decreased by $21.4 \%$ in model group $(71.2 \pm 3.8)(P<0.01)$. After treatment with TIMP1, the vertical migration of cells $(85.3 \pm 3.7)$ increased compared with that in model group but failed to recover to the level of control group $(P<0.01)$ (Figure 4$)$.

\section{Discussion}

Fibroblasts are major repair cells in the skin, which account for $40 \%$ to $60 \%$ of total cells. The biological effects of fibroblasts play vital roles in wound healing [19]. Scholars have found that the DNA synthesis of skin fibroblasts significantly decreased, while apoptosis increased, in patients with diabetes, which indicates that the proliferation of fibroblasts was inhibited in the pathological statement of diabetes [20]. Studies in rats demonstrated similar results to those in humans [21]. However, whether the changes in biological behaviors of fibroblasts are related to high MMP9 expression in the diabetes is still unknown.

To avoid the complicating factors in vivo, high concentrations of glucose and homocysteine were used to mimic the local environment of diabetic skin [12]. Results of this study showed that MMP9 expressions of fibroblasts increased when cultured in high glucose and high homocysteine medium. The expressions of MMP9 mRNA, protein levels, and protease activity in high-glucose and high-homocysteine-treated group were 6.05-, 4.12-, and 1.62-fold, respectively, higher than those in control group, which suggested that high expression of MMP9 was induced.

At the same time, the S-phase cell ratio, proliferation index and cell viability in high-glucose and high-homocysteine-treated group decreased significantly compared with those in control group. After treatment by TIMP1, expression of MMP9 mRNA and protein levels had no statistical change, but activity of MMP9 protein was inhibited significantly, together with the increase of S-phase cell ratio, proliferation index, and cell viability. These results suggested that the inhibition of fibroblasts proliferation and viability were likely related with the high activity of MMP9.

Wound healing depends on the fibroblasts proliferation, migration, granulation tissue formation, collagen secretion, and collagen-based scar formation, which need the participation of many different cells [22]. As fibroblasts are the most important cells of collagen synthesis [23], barriers of proliferation and vitality inevitably have negative effects on new collagen synthesis and wound healing. The present study found that, compared with that in control group, the amount of hydroxyproline in model group decreased by $68.7 \%$. After treatment by TIMP1, the hydroxyproline synthesis increased. The result suggested that in the diabetic status, not only did high protease activity of MMP9 increase the degradation of extracellular matrix [24] but also the collagen synthesis was decreased because of the decrease in the number and activity of fibroblasts. Thus the collagen metabolism was kept in negative balances and will ultimately delay the healing of diabetic wounds.

Migration is another biological property of fibroblasts [25]. It is generally accepted that there is a positive correlation between expression of MMP9 and migration behavior of cells $[26,27]$. In our study, it is very interesting that both the horizontal and vertical migration abilities of fibroblasts were significantly decreased in model group. The possible mechanisms of this phenomenon may be as follows. Firstly, high expression of MMP9 may result in excessive matrix protein degradation, which is necessary to support the migration of fibroblasts. Our previous data showed that the expression level of MMP9 of the skin was significantly enhanced during wound healing in diabetic rats [4-6]. Reiss et al. [28] further demonstrated that exogenous MMP9 directly delayed wound healing in a mouse model. Secondly, increased activity of MMP9 is capable of cleaving nonmatrix proteins [29], which are essential to the migration of cells [30]. Kyriakides et al. [31] found that antibody-based blockade of MMP9 function or MMP9 deficiency retarded migration, and the rate of reepithelialization was significantly delayed in MMP9 knockout mice when compared with wide-type mice. In this study, the migration ability of fibroblasts in model group decreased, which will prevent fibroblasts from crawling to the site of wound in time to play their roles. Because the inhibition of fibroblasts proliferation, viability, and collagen synthesis, even if they migrate to the site of wound, they still cannot function normally-they cannot proliferate efficiently to make up adequate cells and they can not produce enough extracellular matrix and cell factors, so that the normal cycle of wound healing is broken, and this will cause the disorder of wound healing. 


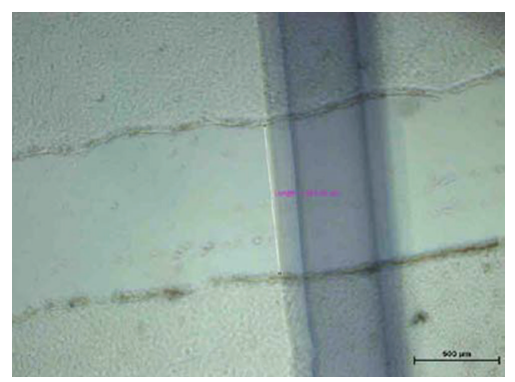

(a)

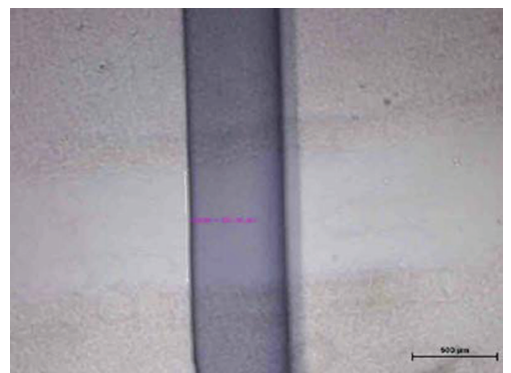

(d)

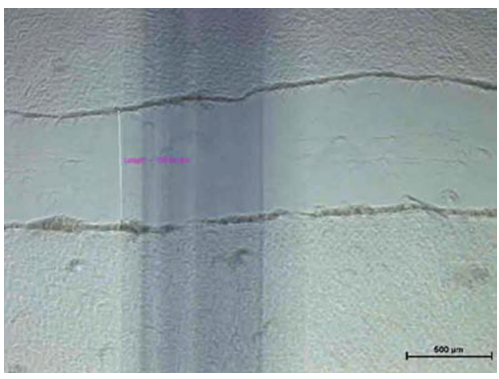

(b)

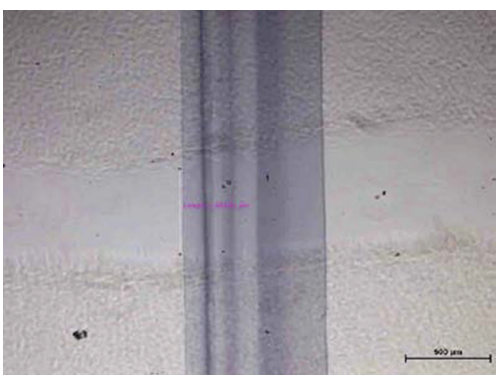

(e)

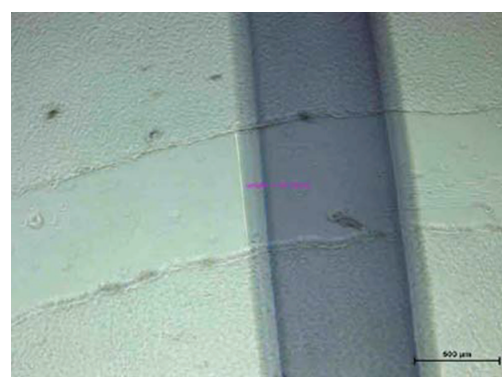

(c)

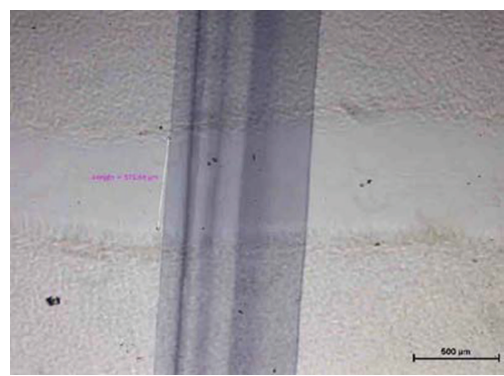

(f)

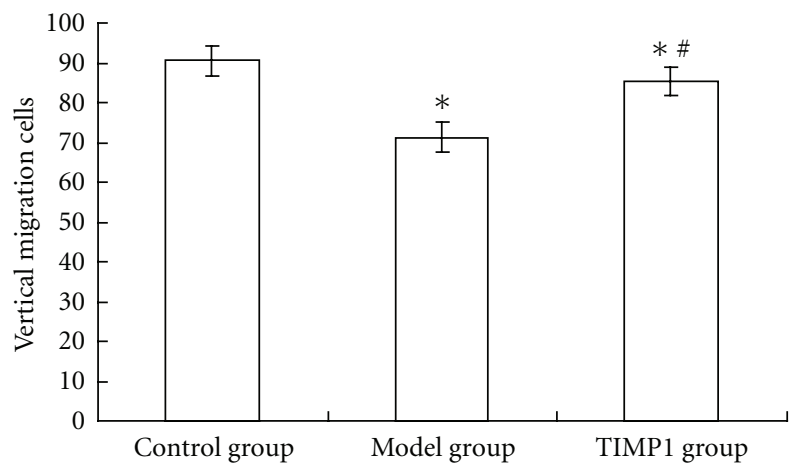

(g)

Figure 3: Scratch test of each group. (a) Control group $0 \mathrm{~h}(\times 40)$; (b) model group $0 \mathrm{~h}(\times 40)$; (c) tissue inhibitor of metalloproteinase 1 (TIMP1) group $0 \mathrm{~h}(\times 40)$; (d) control group $6 \mathrm{~h}(\times 40)$; (e) model group $6 \mathrm{~h}(\times 40)$; (f) TIMP1 group $6 \mathrm{~h}(\times 40)$; $(\mathrm{g})$ histogram. The horizontal migration rate of fibroblasts in model group was lower than that in control group with the inhibition rate being $45.0 \%$. After treatment with TIMP1, the horizontal migration rate increased compared with that in model group, but failed to recover to the level of control group. ${ }^{*} P<0.01$ versus control group; ${ }^{\#} P<0.01$ versus model group. Data are mean \pm SEM, $n=5$.

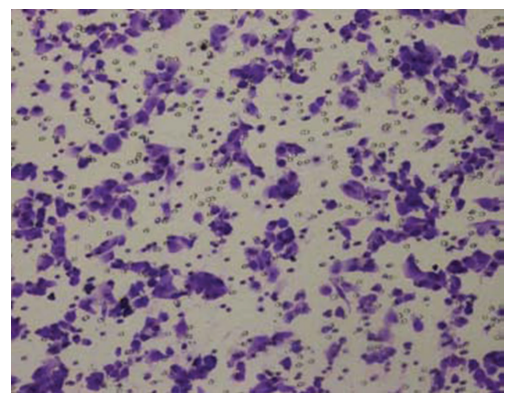

(a)

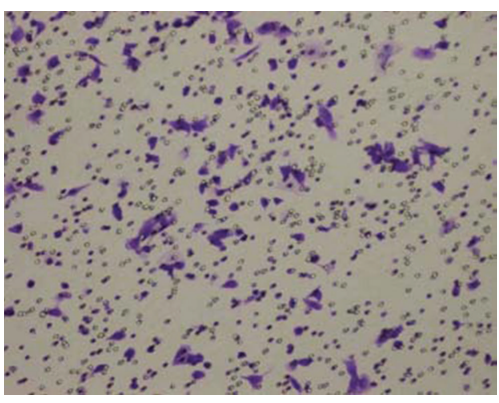

(b)

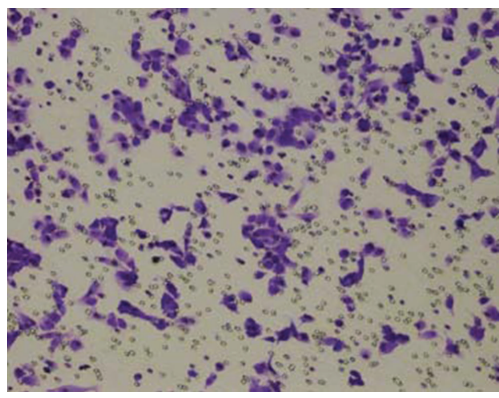

(c)

Figure 4: Vertical migration of fibroblasts. (a) Control group $(\times 100)$; (b) model group $(\times 100)$; (c) tissue inhibitor of metalloproteinase 1 (TIMP1) group $(\times 100)$. Compared with control group, the vertical migration of cells decreased by $21.4 \%$ in model group. After treatment with TIMP1, the vertical migration of cells increased compared with that in model group but failed to recover to the level of control group. 


\section{Conclusion}

In our previous studies, fibroblasts exhibited an upregulation of MMP9 as a result of high glucose and high homocysteine incubation $[10,11]$. The present study further proved that the biological behaviors of rat dermal fibroblasts can be inhibited by high level of MMP9, and the inhibited effect can be reduced by TIMP1, which can inhibit the activity of MMP9. So we believe that inhibiting the activity of MMP9 may be a feasible way to accelerate the healing of diabetes skin ulcers. However, the delayed wound healing is a complicated procedure, and the potential involvement of other MMP and TIMP family members and related cytokines still needs further investigation.

Deficiencies: The present study is performed in vitro, and the results of this research remain to be further confirmed in future animal experiments.

\section{Conflict of Interests}

The authors report no conflict of interests.

\section{Authors' Contribution}

S.-N. Xue, J. Lei, C. Yang, and L. Yan designed and coordinated the experiments and prepared the paper. S.-N. Xue and D.-Z. Lin performed the research/study. J. Lei managed the literature searches and undertook the statistical analysis.

\section{Acknowledgments}

This work is supported by a grant from the National Natural Science Foundation of China (81070660) and the Science and Technology Project Foundation of Guangdong Province (2008A030201012 and 2009B091300128). The authors are grateful to Dr. Ping Zhu and Dr. Xiao-ying Xie for their contribution to part of the study. They are grateful to Dr. LiHong Chen and Dr. Meng Ren for critical review of the paper.

\section{References}

[1] Z. R. Xu, "Prevention and treatment of diabetic foot disease," Chinese Journal of Diabetes Mellitus, vol. 1, no. 5, pp. 386-389, 2009.

[2] R. Lobmann, A. Ambrosch, G. Schultz, K. Waldmann, S. Schiweck, and H. Lehnert, "Expression of matrix-metalloproteinases and their inhibitors in the wounds of diabetic and non-diabetic patients," Diabetologia, vol. 45, no. 7, pp. 10111016, 2002.

[3] M. Muller, C. Trocme, B. Lardy, F. Morel, S. Halimi, and P. Y. Benhamou, "Matrix metalloproteinases and diabetic foot ulcers: the ratio of MMP-1 to TIMP-1 is a predictor of wound healing," Diabetic Medicine, vol. 25, no. 4, pp. 419-426, 2008.

[4] L. Yan, P. Zhu, L. H. Chen et al., "Imbalance of MMP9/TIMP1 during the cutaneous "underlying diorder" in diabetic rats," Chinese Journal of Endocrinology and Metabolism, vol. 24, no. 5, pp. 533-537, 2008.

[5] P. Zhu, L. Yan, L. H. Chen et al., "Imbalance between matrix metalloproteinases and tissue inhibitor of metalloproteinases during wound healing in diabetic rats," Chinese Journal of Pathophysiology, vol. 24, no. 11, pp. 2204-2208, 2008.

[6] C. Yang, P. Zhu, L. Yan, L. Chen, R. Meng, and G. Lao, "Dynamic changes in matrix metalloproteinase 9 and tissue inhibitor of metalloproteinase 1 levels during wound healing in diabetic rats," Journal of the American Podiatric Medical Association, vol. 99, no. 6, pp. 489-496, 2009.

[7] J. Khoshnoodi, V. Pedchenko, and B. G. Hudson, "Mammalian collagen IV," Microscopy Research and Technique, vol. 71, no. 5, pp. 357-370, 2008.

[8] S. C. Wu, V. R. Driver, J. S. Wrobel, and D. G. Armstrong, "Foot ulcers in the diabetic patient, prevention and treatment," Vascular Health and Risk Management, vol. 3, no. 1, pp. 65-76, 2007.

[9] R. Visse and H. Nagase, "Matrix metalloproteinases and tissue inhibitors of metalloproteinases: structure, function, and biochemistry," Circulation Research, vol. 92, no. 8, pp. 827839, 2003.

[10] S. N. Xue, J. Lei, D. Z. Lin et al., "Establishment of a cell model with high expression of MMP9," Chinese Journal of Health Laboratory Technology, vol. 21, no. 1, pp. 82-84, 2011.

[11] L. H. Chen, X. Y. Xie, C. Yang et al., "Effects of high glucose and homocysteine on expression of MMP9 in rat fibroblasts," Chinese Journal of Pathophysiology, vol. 26, no. 9, pp. 1839$1843,2010$.

[12] A. Solini, E. Santini, M. Nannipieri, and E. Ferrannini, "High glucose and homocysteine synergistically affect the metalloproteinases-tissue inhibitors of metalloproteinases pattern, but not TGFB expression, in human fibroblasts," Diabetologia, vol. 49, no. 10, pp. 2499-2506, 2006.

[13] W. J. Piotrowski, P. Gorski, T. Pietras et al., "The selected genetic polymorphisms of metalloproteinases MMP2, 7, 9 and MMP inhibitor TIMP2 in sarcoidosis," Medical Science Monitor, vol. 17, no. 10, pp. CR598-CR607, 2011.

[14] F. Takata, S. Dohgu, J. Matsumoto et al., "Brain pericytes among cells constituting the blood-brain barrier are highly sensitive to tumor necrosis factor- $\alpha$, releasing matrix metalloproteinase- 9 and migrating in vitro," Journal of Neuroinflammation, vol. 8, p. 106, 2011.

[15] H. Y. Dai, L. Liu, S. K. Qin, X. M. He, and S. Y. Li, "Lobaplatin suppresses proliferation and induces apoptosis in the human colorectal carcinoma cell Line LOVO in vitro," Biomedicine and Pharmacotherapy, vol. 65, no. 3, pp. 137-141, 2011.

[16] P. Yu, Z. Wang, X. Sun et al., "Hydrogen-rich medium protects human skin fibroblasts from high glucose or mannitol induced oxidative damage," Biochemical and Biophysical Research Communications, vol. 409, no. 2, pp. 350-355, 2011.

[17] M. Cáceres, A. Romero, M. Copaja, G. Díaz-Araya, J. Martínez, and P. C. Smith, "Simvastatin alters fibroblastic cell responses involved in tissue repair," Journal of Periodontal Research, vol. 46, no. 4, pp. 456-463, 2011.

[18] N. Dioufa, A. V. Schally, I. Chatzistamou et al., "Acceleration of wound healing by growth hormone-releasing hormone and its agonists," Proceedings of the National Academy of Sciences of the United States of America, vol. 107, no. 43, pp. 18611-18615, 2010.

[19] S. I. Andreea, C. Marieta, and D. Anca, "AGEs and glucose levels modulate type I and III procollagen mRNA synthesis in dermal fibroblasts cells culture.," Experimental Diabetes Research, vol. 2008, Article ID 473603, 2008.

[20] Y. Niu, T. Xie, K. Ge, Y. Lin, and S. Lu, "Effects of extracellular matrix glycosylation on proliferation and apoptosis of human dermal fibroblasts via the receptor for advanced glycosylated 
end products," American Journal of Dermatopathology, vol. 30, no. 4, pp. 344-351, 2008.

[21] M. J. Wang, S. L. Lu, C. Qing et al., "Effects of different courses of disease on the biological behavior of dermal fibroblasts in diabetic rats," Acta Universitatis Medicinalis Secondae Shanghai, vol. 25, no. 5, pp. 459-462, 2005.

[22] M. Toriseva and V. M. Kähäri, "Proteinases in cutaneous wound healing," Cellular and Molecular Life Sciences, vol. 66, no. 2, pp. 203-224, 2009.

[23] G. S. Schultz and A. Wysocki, "Interactions between extracellular matrix and growth factors in wound healing," Wound Repair and Regeneration, vol. 17, no. 2, pp. 153-162, 2009.

[24] E. Vassiliadis, S. S. Veidal, N. Barascuk et al., "Measurement of matrix metalloproteinase 9-mediated Collagen type III degradation fragment as a marker of skin fibrosis," BMC Dermatology, vol. 11, article 6, 2011.

[25] M. Bindschadler and J. L. McGrath, "Sheet migration by wounded monolayers as an emergent property of single-cell dynamics," Journal of Cell Science, vol. 120, no. 5, pp. 876-884, 2007.

[26] E. A. O’Toole, R. Van Koningsveld, M. Chen, and D. T. Woodley, "Hypoxia induces epidermal keratinocyte matrix metalloproteinase-9 secretion via the protein kinase C pathway," Journal of Cellular Physiology, vol. 214, no. 1, pp. 47-55, 2008.

[27] K. A. Scott, C. H. Arnott, S. C. Robinson et al., "TNF- $\alpha$ regulates epithelial expression of MMP-9 and integrin $\alpha \mathrm{v} \beta 6$ during tumour promotion. A role for TNF- $\alpha$ in keratinocyte migration?" Oncogene, vol. 23, no. 41, pp. 6954-6966, 2004.

[28] M. J. Reiss, Y. P. Han, E. Garcia, M. Goldberg, H. Yu, and W. L. Garner, "Matrix metalloproteinase-9 delays wound healing in a murine wound model," Surgery, vol. 147, no. 2, pp. 295-302, 2010.

[29] R. Lobmann, G. Schultz, and H. Lehnert, "Proteases and the diabetic foot syndrome: mechanisms and therapeutic implications," Diabetes Care, vol. 28, no. 2, pp. 461-471, 2005.

[30] R. K. Sivamani, M. S. Garcia, and R. Rivkah Isseroff, "Wound re-epithelialization: modulating keratinocyte migration in wound healing," Frontiers in Bioscience, vol. 12, no. 8, pp. 2849-2868, 2007.

[31] T. R. Kyriakides, D. Wulsin, E. A. Skokos et al., "Mice that lack matrix metalloproteinase-9 display delayed wound healing associated with delayed reepithelization and disordered collagen fibrillogenesis," Matrix Biology, vol. 28, no. 2, pp. 65-73, 2009. 


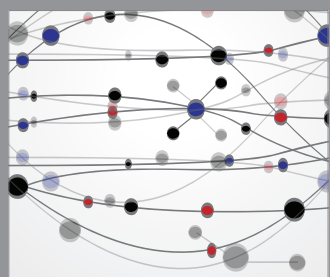

The Scientific World Journal
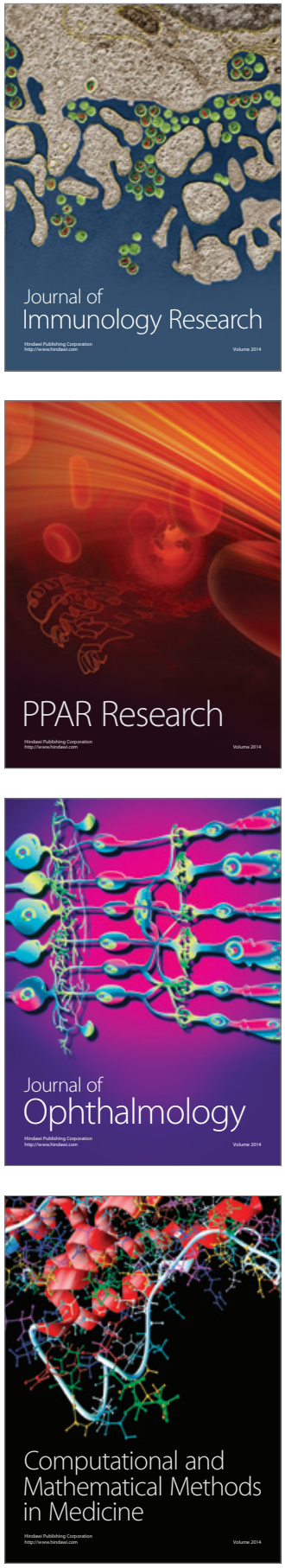

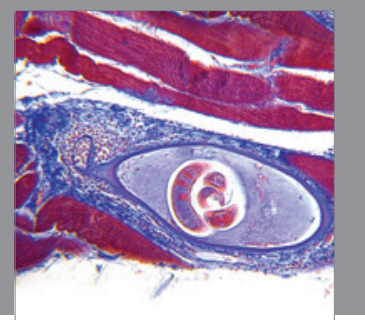

Gastroenterology

Research and Practice
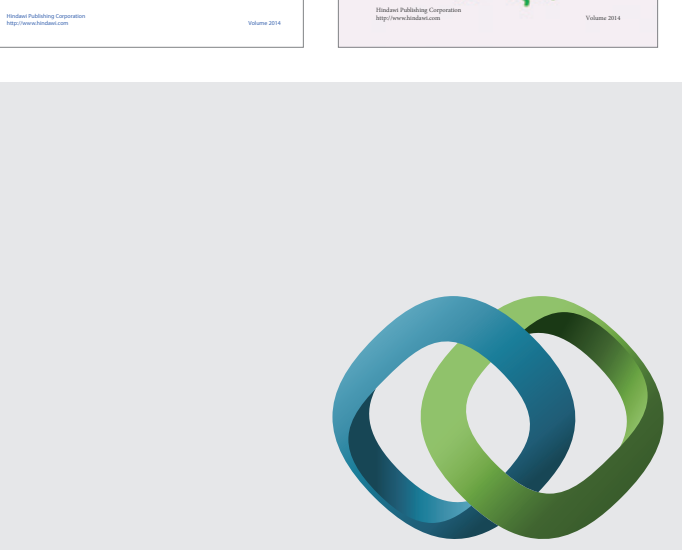

\section{Hindawi}

Submit your manuscripts at

http://www.hindawi.com
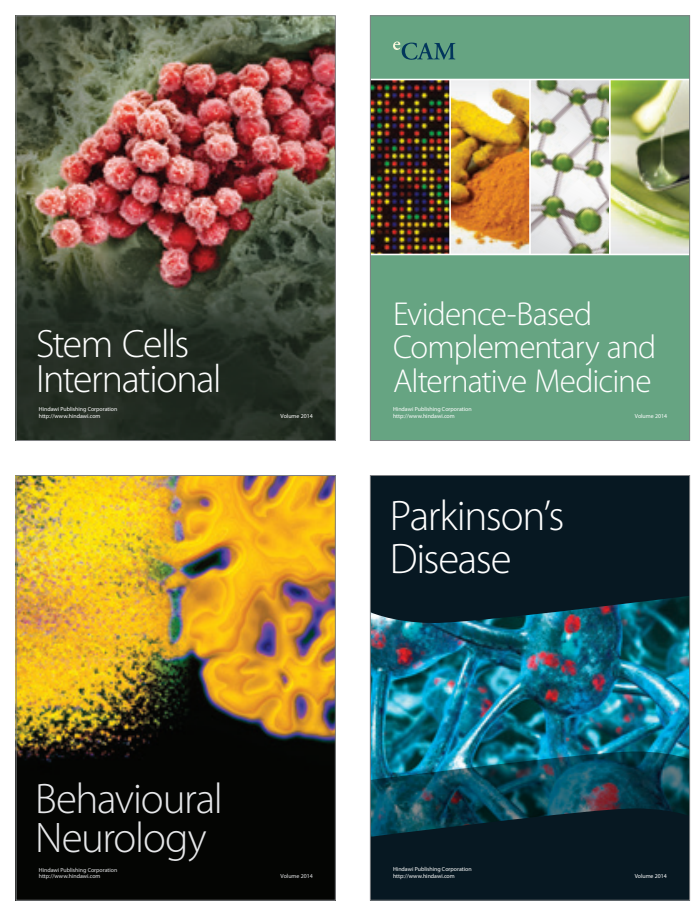

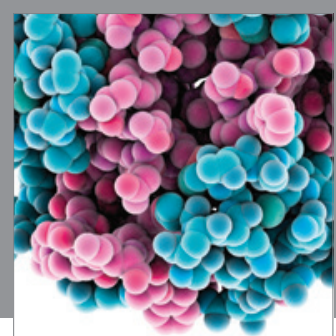

Journal of
Diabetes Research

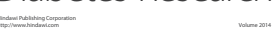

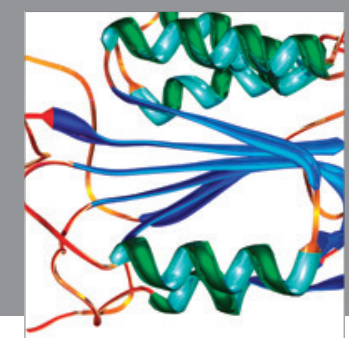

Disease Markers
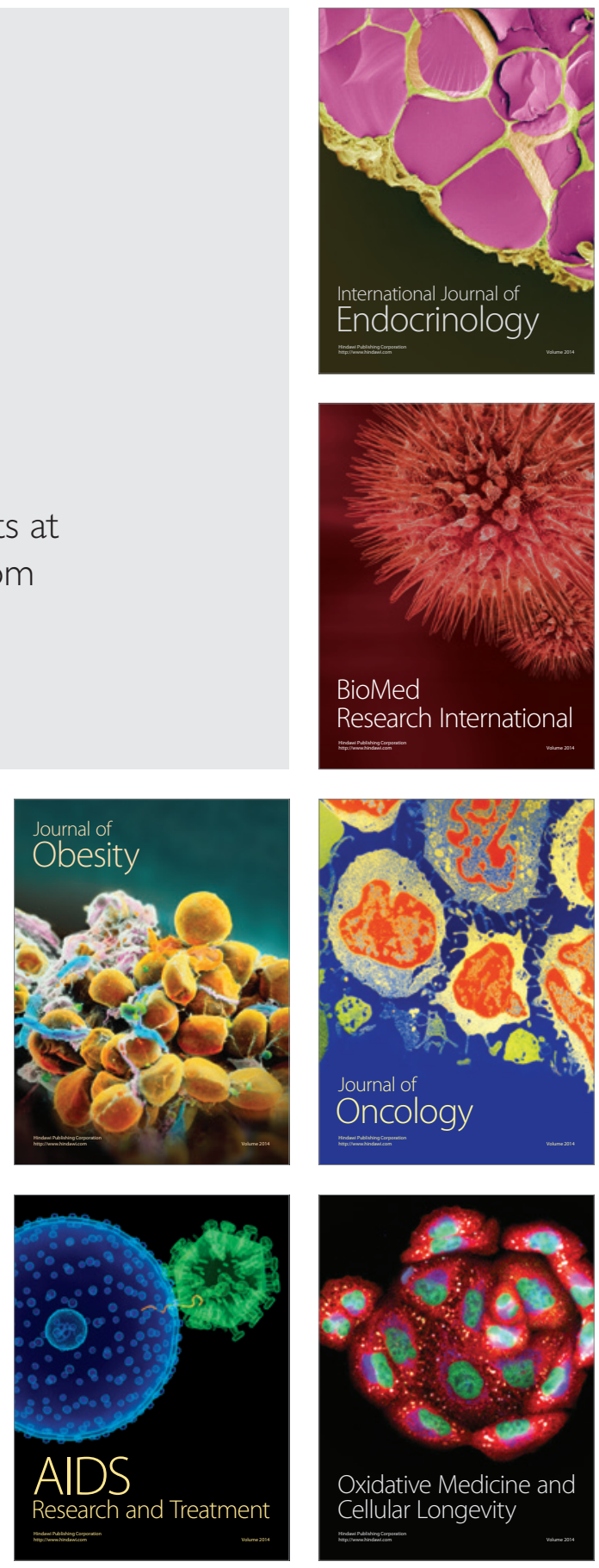